\title{
História do jornalismo paulista: o inventário de Affonso A. de Freitas nas comemorações do centenário da imprensa periódica de São Paulo e os jornais em língua estrangeira
}

Alvaro Daniel COSTA ${ }^{1}$

Resumo:

O artigo pretende investigar, por meio da conexão com a palavra impressa e a história da mídia, a comemoração do centenário da imprensa periódica paulista a partir dos periódicos editados em língua estrangeira. Em um período de festa devido ao centenário da imprensa brasileira, o Instituto Histórico e Geográfico Brasileiro (IHGB) resolveu planejar uma publicação de um inventário metódico que contemplasse todos os jornais já produzidos no país. Cada estado teria um responsável e no estado de São Paulo o escolhido foi Affonso A. De Freitas, que listou todos os periódicos em A Imprensa Periódica de São Paulo de seus primórdios em 1823 até 1924 por Affonso A. De Freitas. Na segunda metade do século XIX e início do século XX, a onda migratória aumentou no estado e fez surgir vários jornais destinados a essa nova camada da população paulistana. Destacam-se os jornais italianos, espanhóis, franceses, sírios e alemães, além dos já tradicionais impressos brasileiros.

Palavras-chave: história do jornalismo; IHGB; jornais paulistas; jornais em língua estrangeira em São Paulo; Affonso A. de Freitas.

\section{São Paulo's journalism history: Affonso A. de Freitas' inventory at the centenary celebrations of São Paulo's periodical press and the foreign language newspapers}

\begin{abstract}
:
This article seeks to investigate, through the connection with Brazilian media and press history, the centenary celebrations of São Paulo's periodical press drawing on the periodicals edited in a foreign language. In a time of celebration due to Brazilian press centenary, the Instituto Histórico e Geográfico Brasileiro (IHGB) decided to arrange the publication of a systematic inventory that would include all the newspapers that had been produced in the country. Each state would have one representative in the state of São Paulo this was Affonso A De Freitas, who listed all the periodicals in his A Imprensa Periódica de São Paulo de seus primórdios em 1823 até 1924 por Affonso A. De Freitas. In the second half of 19th century and beginning of 20th century the migration increased in the state and led to the appearance of several newspapers destined to this new stratum of the São Paulo population. The Italian, Spanish, French, Syrian and German newspapers stand out, in addition to the already trational Brazilian newspapers.
\end{abstract}

Keywords: history of journalism; IHGB; São Paulo newspapers; foreign language newspapers in São Paulo; Affonso A. de Freitas.

\section{Historia del periodismo paulista: el inventario de Affonso A. de Freitas en las celebraciones del centenario de la prensa periódica de São Paulo y de los periódicos en lengua extranjera}

\section{Resumen:}

El artículo pretende investigar, a través de la conexión con la palabra impresa y la historia de los medios de comunicación, la celebración del centenario de la prensa periódica paulista a partir de publicaciones periódicas en lengua extranjera. En un período de celebración debido al centenario de la prensa brasileña, el Instituto

\footnotetext{
${ }^{1}$ Doutorando em História pela Universidade Estadual do Oeste do Paraná (UNIOESTE) e mestre em História pela Universidade Estadual de Ponta Grossa (UEPG).E-mail: alvarominogue@ hotmail.com
} 
Histórico e Geográfico Brasileiro (IHGB) decidió planificar la publicación de un inventario metódico que incluiría todos los periódicos producidos en el país. Cada estado tendría un responsable y en el estado de São Paulo el elegido fue Affonso A. de Freitas, quien enumeró todas las publicaciones periódicas en A Imprensa Periódica de São Paulo de seus primórdios em 1823 até 1924 por Affonso A. De Freitas. En la segunda mitad del siglo XIX y principios del XX, la ola migratoria aumentó en el estado y dio lugar a varios periódicos dirigidos a esta nueva capa de la población paulistana. Destacan los periódicos italianos, españoles, franceses, sirios y alemanes, además de la ya tradicional prensa brasileña.

Palabras clave: historia del periodismo; IHGB; los periódicos de São Paulo; periódicos en lengua extranjera en São Paulo; Affonso A. de Freitas.

\section{O início de tudo}

A chegada da família real em 1808 foi certamente um ponto essencial para a história do Brasil. Dentre as transformações, podem-se citar a mudança do status jurídico de colônia para reino unido, abertura dos portos e a chegada da prensa tipográfica. Antes da vinda da família real não existiram tipografias consolidadas, contudo, a chegada de Dom João VI muda o que se entende por circulação impressa no país. Enquanto na Europa a imprensa já existia desde o século XV, no Brasil demora mais de 300 anos para seu surgimento.

De acordo com Costa (2017, p. 14) “a chegada da Imprensa Régia permitiu, para além de uma proliferação dos impressos, a expansão do mundo letrado, dando novos sentidos ao mundo narrado, mesmo que fosse mesclado com uma cultura oral”. Sobre isso, Barbosa (2013, p. 97) relembra:

O mundo da impressão invadia cidades, vilas, lugares distantes da Corte e pelos periódicos tomava-se conta do que acontecia, não apenas nas províncias, mas em terras distantes. Tomar conhecimento do que estava escrito naqueles impressos era participar do mundo.

Apesar de chegar ao Brasil somente no século XIX, a imprensa logo se conecta a esse período de intensas mudanças no mundo, sendo o jornalismo impresso um dos fatores que mais contribuíram nessas modificações sociais, culturais e políticas. Especificamente no Brasil, uma mudança primordial se deu no âmbito das pesquisas científicas, históricas e culturais, com o surgimento do Instituto Histórico e Geográfico Brasileiro (IHGB), em 1838. Além de realizar diversos estudos, a instituição teve por objetivo a construção de uma nova nação que surgia. Até o século XIX, muito pouco tinha se produzido sobre uma história nacional, cabendo, portanto, ao IGHB a confecção desses materiais.

Em 1908, a Revista do Instituto Histórico e Geográfico Brasileiro publicou o Tomo Consagrado à Exposição Commemorativa do Primeiro Centenário da Imprensa Periódica no Brasil. Um dos principais escopos dessa edição especial era a preparação de um inventário 
que contemplasse todos os jornais até então publicados, no período que compreendia de 1808 até o ano de 1907.

A primeira parte do volume I tinha por propósitos:

$1^{\circ}$ Exposição de todos os jornaes publicados no Brazil, no século decorrido de 1808 a 1907 (31 de dezembro); 2 Publicação de uma monografia, ou memoria histórica sobre a gênese e os progressos da Imprensa periódica no Brazil; $3^{\circ}$ Publicação de um catalogo methodico de todos os specimens, ou collecções que figurarem na Exposição $4^{\circ}$ Cunhagem de uma medalha comemorativa (REVISTA DO INSTITUTO..., 1908, p. 8).

Deve-se mencionar que os produtores desses catálogos eram os intelectuais do seu período. Figuraram entre os responsáveis pela elaboração dos catálogos, profissionais médicos, engenheiros, advogados, políticos e outros, que, de acordo com Coelho (1999, p. 9), eram intitulados como sendo "profissões imperiais".

Como resultado desse empreendimento, foi publicado no centenário da imprensa um catálogo de jornais das regiões Norte e Nordeste que totalizou 821 páginas, nas quais se descreve sumariamente cada periódico que já existiu no Brasil.

\section{A comemoração dos cem anos}

Os cem anos da imprensa periódica foram relevantes para a história do Brasil, pois os jornais corroboraram o desenvolvimento do país, tendo nas suas páginas as provas do seu progresso. Pode-se afirmar que os periódicos fazem parte da história como fonte, ao registrarem momentos de um determinado tempo.

As mostras documentais comemorativas organizadas pelo IHGB acabaram por ajudar no processo de compreensão da história e da geografia do país. Apesar da efemeridade das exposições, os catálogos, guias e cartazes propiciaram caráter de permanência ao trabalho realizado para a exposição, demonstrando, assim, a perpetuidade e a importância de documentar, mesmo que sumariamente, os jornais publicados no país. Ainda que fossem catálogos sumários, ${ }^{2}$ eles tinham função, na lógica comemorativa, de ser um instrumento de poder da memória e de construir materialmente a história dos jornais e também do Brasil.

Os catálogos do centenário tratam do passado, contudo, pensando no presente (comemoração em 1908) e sendo uma aposta para o futuro, por se tratar de um inventário do jornalismo do país. Publicar esses catálogos foi um modo de colaborar não só com a escrita da

\footnotetext{
${ }^{2}$ Espécie de catálogo que contém informações básicas ou principais.
} 
história do Brasil, mas com a memória jornalística e com o método histórico. Deve-se pontuar que a História, como ciência, estava se afirmando no mundo, e as pesquisas produzidas pelos membros do IHGB foram essenciais. Os periódicos até então surgidos no Brasil se converteriam em vestígios para a escrita da História e se tornariam fontes para futuras pesquisas.

Diz Costa (2020, p. 5):

Os catálogos festivos referentes ao centenário da imprensa poderiam se encaixar também como patrimônio documental. $\mathrm{O}$ empenho do Instituto, não somente na procura, mas também pela produção de informações que lançassem luz sobre à história do Brasil fez estimular a publicação dos anos do centenário.

Conforme Costa (2020, p. 6), "um dos principais objetivos de comemorar é despertar, com determinado sentimento de alegria e euforia, algum feito histórico ou algo que ficou marcado no tempo. Por trás de uma comemoração, existe um simbolismo". Ainda de acordo com Costa (2020, p. 6) "eram comuns, no século XIX, festividades que marcavam a comemoração de fatos da história de uma nação ainda em processo de formação".

Um exemplo de comemoração trazido por Costa (2020, p. 6) é a coroação de Dom João e o casamento de Dom Pedro I.

Em Portugal, muitos centenários foram festejados na segunda metade do século XIX. É o caso do nascimento do Marquês de Pombal, das festas dos descobrimentos marítimos portugueses, da lembrança da morte de Padre Antônio Vieira, dentre tantas outras rememorações.

A sociedade de Portugal copiou seus vizinhos da Europa na tradição dos festejos de centenários, e por aqui essa prática também teve aderência. Posteriormente, a ideia de centenário vai se expandir para a comemoração de bicentenários e assim por diante.

Segundo Gonçalves (2010, p. 2), a historicização acerca da cultura das festas pode ser analisada por diversas variantes. Pode-se dizer que as festas ao longo da história serviram como uma forma de celebração do sagrado, ou seja, tinham na religião uma espécie de rito para suas crenças. As celebrações também serviam como uma forma de divulgação da imagem de alguns monarcas, ou seja, possuíam uma finalidade política (principalmente no Antigo Regime), que, segundo Gonçalves (2010, p. 6), "possuíam um caráter multifuncional”, pois poderia ser comemorado tanto um fato religioso como político, entre outros.

Segundo Costa (2020, p. 5), no Brasil, “as cerimônias eram bens de prestígio e se 
tornaram cada vez mais comuns com o exílio da corte portuguesa. Várias datas se tornaram pretexto para comemorações e rememorações". Além disso, as festas poderiam ser entendidas como um momento de práticas de sociabilidades em que interagiam diversas camadas da sociedade. Muitas dessas festas resultavam, ainda, em exposições artísticas, históricas ou científicas que tinham o intuito de reunir materiais que pudessem contar e comprovar a história do Brasil, como, por exemplo, objetos, documentos, jornais.

Na visão de Costa (2020, p. 6),

$\mathrm{O}$ ato comemorativo tinha outro aspecto substancial para além da questão da unidade nacional: o conhecimento por regiões. Com os estudos e os catálogos regionais, o conhecimento sobre o Brasil se expandiu, não se restringindo apenas aos grandes centros, como algumas capitais e cidades litorâneas.

Foi assim que alguns estados brasileiros lançaram seus inventários nos cem anos de imprensa periódica, como foi o caso dos estados do Paraná, em 1908, e de São Paulo, em 1915. Pode-se dizer que os catálogos comemorativos dos cem anos de imprensa fornecem subsídios para o estudo da história da leitura, história do jornalismo e também das redes de comunicação formadas no país.

IHGB na construção de uma história da mídia e o catálogo de jornais paulistas de Affonso A. de Freitas

A metodologia empregada para este artigo foi a leitura dos catálogos do centenário, análise dos dados e identificação dos títulos dos jornais em língua estrangeira para a análise quantitativa e descritiva.

No IHGB, fatos e datas comemorativas motivaram a confecção de estudos monográficos. Como já mencionamos, esse foi o caso da história do jornalismo, e coube ao IHGB publicar um documento que contemplasse todos os periódicos já produzidos durante os primeiros cem anos da imprensa no Brasil. No estado de São Paulo, o responsável pela confecção do catálogo foi Alfredo Affonso A. de Freitas, que publicou em 1915 a obra $A$ Imprensa Periódica de São Paulo de seus primórdios em 1823 até 1924 por Affonso A. de Freitas, fruto da pesquisa encomendada pelo IHGB. Para os fins deste artigo, iremos considerar apenas os jornais existentes até 1908.

A obra de Affonso A. de Freitas não se limitou a catalogar as publicações existentes até o ano de 1908 e contemplou o período até 1914. Os jornais do estado de São Paulo, como 
já mencionado, fariam parte do segundo volume das comemorações do centenário da imprensa periódica brasileira, mas depois de uma exaustiva busca, chegou-se à conclusão de que essa edição nunca saiu. Paraná e Pernambuco publicaram suas edições avulsas já em 1908; o catálogo de São Paulo, no entanto, foi lançado em 1915, sete anos após a comemoração do centenário.

O responsável pelo catálogo, Affonso A. de Freitas, contabilizou 1496 títulos, o que demonstra a força da imprensa paulista no Brasil. Ao contrário das outras edições avulsas e do próprio Tomo, o catálogo paulista é mais minucioso, com dados mais ricos em detalhes. Muitos dos jornais catalogados tiveram o registro de uma pequena história de sua origem, de seu posicionamento editorial, informações sobre o proprietário, a tipografia em que foram produzidos, entre outros dados.

Assim como na parte I do Tomo Consagrado à Exposição Commemorativa do Primeiro Centenário da Imprensa Periódica no Brasil e nos catálogos regionais dos estados do Paraná e de Pernambuco, o catálogo paulista começa com uma genealogia da história da imprensa. Freitas (1915) inicia o catálogo mencionando que a imprensa, assim como outros inventos humanos, foi decorrência de uma necessidade da sociedade, surgindo em um contexto favorável, no qual determinadas demandas precisavam ser atendidas. Para o autor, a comunicação escrita por meio da imprensa surgiu a partir da vontade de tornar algo público. Afirma Freitas (1915, p. 3):

Estas necessidades começou o homem, natureza eminentemente sociável, a sentir desde que entrou no goso da racionalidade: seus pensamentos, comunicados a princípio verbalmente, por interlocução, exigiram em seguida, com o desdobramento, da humanidade em glomerações isoladas e ascendentes em civilisação, novos meios de transmissão, e a escripta appareceu nas inscripções lapidares, na correspondencia epistolar e na producção de trabalhos literários e scientificos, systema que, na realidade assignala o marco millionario da história, sinão da imprensa, em sua restricta accepção, com segurança da arte da publicidade.

A partir daí, Freitas fez uma genealogia da palavra impressa no mundo até chegar na realidade brasileira do século XIX. Freitas $(1915$, p. 8) ponderou, ainda, que os feitos após a vinda da família real, em 1808, foram uma "evolução social". A imprensa paulista surgiu após a Independência, em 1823, e o primeiro título foi o jornal O Paulista, cuja duração foi pequena (menos de um ano), tendo no comando o professor de Gramática Latina e Retórica Antonio Mariano de Azevedo. A imprensa paulista só se instalaria definitivamente em 1827, com o periódico O Farol Paulistano, fundado pelo "Dr. José da Costa Carvalho", que mais 
tarde se tornaria barão de Monte Alegre.

De acordo com a primeira parte da publicação especial do Tomo Consagrado à Exposição Commemorativa do Primeiro Centenário da Imprensa Periódica no Brazil, existiram no país aproximadamente 25 mil títulos de jornais; verificaram-se 5277 títulos que contemplavam as regiões Norte e Nordeste, excetuando o estado da Bahia. Se levarmos em consideração os catálogos publicados avulsamente (Paraná e São Paulo), esse número pula para 7003 títulos.

Todavia, o projeto de publicação de um catálogo geral não deu certo e resultou apenas em uma versão introdutória, além de outra com os já mencionados estados do Norte e Nordeste e, por fim, a publicação dos inventários paranaense e paulista.

Gráfico 1 - Número de jornais por estado no centenário da imprensa no Brasil

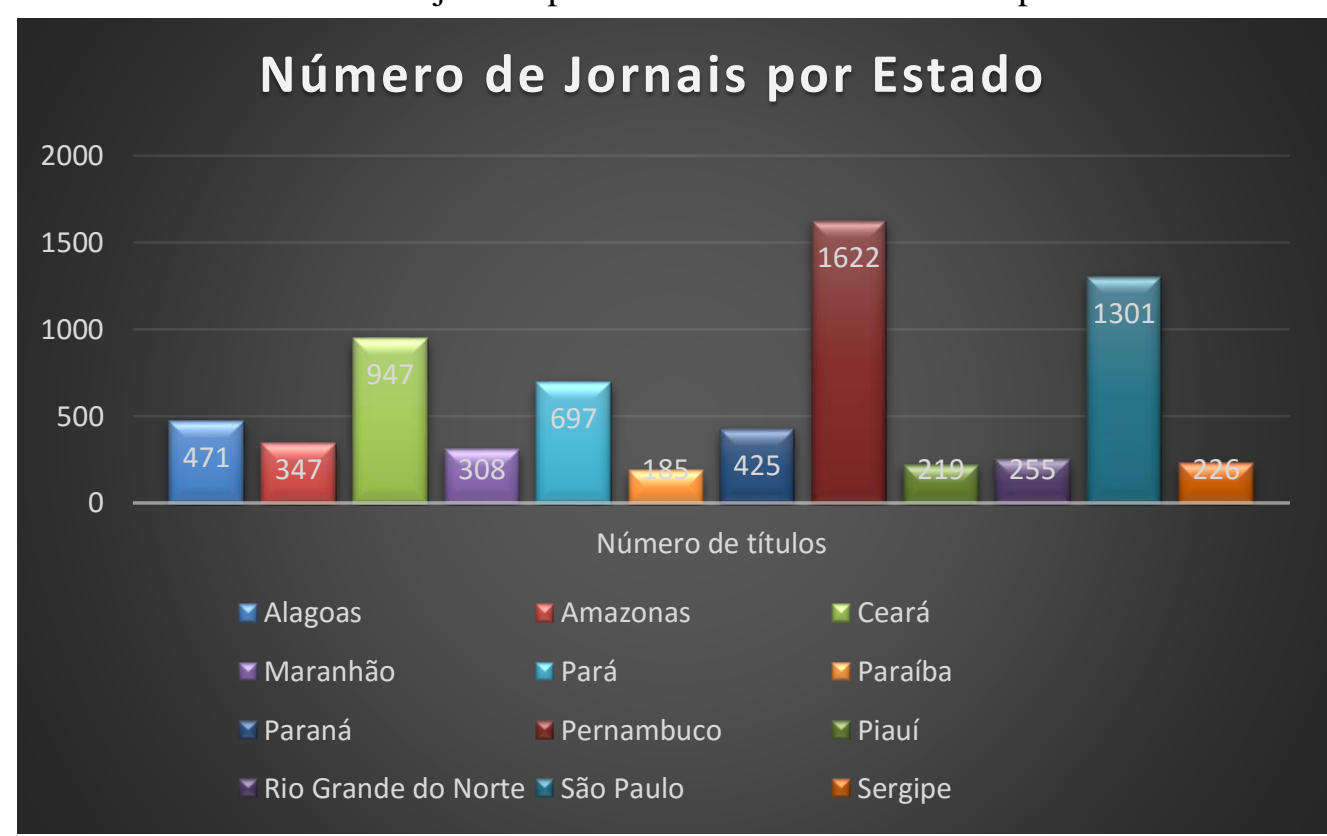

Fonte: Gráfico produzido pelo autor com dados do Tomo Consagrado à Exposição Commemorativa do Primeiro Centenário da Imprensa Periódica no Brasil, do Catalogo de Jornaes Publicados no Paraná de 1853 até 1907 e de A Imprensa Periódica de São Paulo de seus primórdios em 1823 até 1924 por Affonso A. De Freitas.

\section{Os jornais em idioma estrangeiro em São Paulo}

São Paulo foi um estado que teve forte leva de imigrantes na metade do século XIX e início do século XX, sobretudo italianos, franceses, alemães, sírios, portugueses, espanhóis e outras nacionalidades. A vinda de diversos imigrantes se deve à substituição da mão de obra, que, até 1888, era escravista. Klein (1994) aponta que no período de 1834 a 1903 chegaram ao país 549.579 portugueses, 1.778 .577 italianos, 212.218 espanhóis, 87.166 alemães e 275.554 de outras etnias, totalizando 2.903.074 imigrantes no país. 
No final do século XIX, existiu uma vontade entre os governos europeus e brasileiros de incentivar a imigração, devido ao fim da escravidão no Brasil e também pela influência do pensamento positivista de progresso, além de questões relacionadas à eugenia. Nota-se através dos catálogos analisado que com o rápido desenvolvimento do estado de São Paulo, não demoraram a surgir jornais voltados a determinadas culturas, como a italiana, a francesa, a espanhola, a alemã, a síria, entre outras.

Até o centenário da imprensa, a capital de São Paulo teve 1301 títulos de jornais, sendo 161 deles em outro idioma, ou seja, aproximadamente 12,37\% das publicações. De acordo com Affonso A. de Freittas, o primeiro jornal em outra língua a aparecer foi o italiano Centro Industriale e Commerciale Italiano, em 1876. Logo depois, mais títulos surgiram, como Germania, em 1878, e Corriere D'Italia, em 1880. Títulos em francês também tiveram destaque, por exemplo: Revue Française e Revue de Saint-Paul, no ano de 1887; France Au Bre 'sil, em 1891, entre outros. Em língua espanhola, podemos citar os periódicos La Iberia, em 1894; La Gaceta Española, de 1897; La Luz, de 1898; El Grito del Pueblo, surgido em 1899, entre tantos outros. Os jornais sírios também apareceram no catálogo, como os periódicos Al Assmahy, em 1898, e Al-Munazer, em 1899.

Quadro 1 - Jornais em língua estrangeira em São Paulo no centenário da imprensa

\begin{tabular}{|l|l|l|l|}
\hline Jornal & Idioma & Ano & Cidade \\
\hline 1) Centro Industriale e Commerciale Italiano & Italiano & 1876 & São Paulo \\
\hline 2) Germania & Alemão & 1878 & São Paulo \\
\hline 3) Corriere D'Italia & Italiano & 1880 & São Paulo \\
\hline 4) Eco D'Italia & Italiano & 1882 & São Paulo \\
\hline 5) L'Immigrante & Italiano & 1885 & São Paulo \\
\hline 6) La Lotta & Italiano & 1885 & São Paulo \\
\hline 7) Il Gabribaldi & Italiano & 1885 & São Paulo \\
\hline 8) Nuova Roma & Italiano & 1885 & São Paulo \\
\hline 9) O Allioth & Italiano & 1886 & São Paulo \\
\hline 10) Gli Italiani Al Brasile & Italiano & 1886 & São Paulo \\
\hline 11) Gl'Italiani in San Paulo & Italiano & 1886 & São Paulo \\
\hline 12) Il Tevere & Italiano & 1887 & São Paulo \\
\hline 13) Revue Française & Francês & 1887 & São Paulo \\
\hline 14) Revue de Saint- Paul & Francês & 1887 & São Paulo \\
\hline 15) Lega Italiana & Italiano & 1889 & São Paulo \\
\hline 16) Il Fumine & Italiano & 1889 & São Paulo \\
\hline 17) O Volapuk & Volapuque & 1889 & São Paulo \\
\hline 18) Freie Presse & Alemão & 1889 & São Paulo \\
\hline 19) Echo Von Brasilien & Alemão & 1890 & São Paulo \\
\hline 20) Il Pensiero* & Italiano & 1890 & São Paulo \\
\hline 21) Cittadini Italiano & Italiano & 1890 & São Paulo \\
\hline 22) Lingua Universal Volapuk & Volapuque & 1890 & São Paulo \\
\hline 23) Progresso Italo-Brasiliano & Italiano & 1890 & São Paulo \\
\hline
\end{tabular}




\begin{tabular}{|c|c|c|c|}
\hline Jornal & Idioma & Ano & Cidade \\
\hline 24) Deutsch-Brasilianische & Alemão & 1891 & São Paulo \\
\hline 25) Il Mensagero & Italiano & 1891 & São Paulo \\
\hline 26) Correo Español & Espanhol & 1891 & São Paulo \\
\hline 27) France Au Bre'sil & Francês & 1891 & São Paulo \\
\hline 28) Il Simbolismo & Italiano & 1892 & São Paulo \\
\hline 29) Pauliftaner Echo & Alemão & 1892 & São Paulo \\
\hline 30) Diavolo Nero & Italiano & 1892 & São Paulo \\
\hline 31) La Vertenza & Italiano & 1892 & São Paulo \\
\hline 32) Roma & Italiano & 1892 & São Paulo \\
\hline 33) Gli Schiavi Bianchi & Italiano & 1892 & São Paulo \\
\hline 34) Pro Patria & Italiano & 1892 & São Paulo \\
\hline 35) Le Forche Caudine & Italiano & 1892 & São Paulo \\
\hline 36) El Heraldo & Espanhol & 1892 & São Paulo \\
\hline 37) La Patria Italiana & Italiano & 1893 & São Paulo \\
\hline 38) Giustizia & Italiano & 1893 & São Paulo \\
\hline 39) Fanfulla & Italiano & 1893 & São Paulo \\
\hline 40) L'Asino Umano & Italiano & 1893 & São Paulo \\
\hline 41) Il' Lavoro & Italiano & 1893 & São Paulo \\
\hline 42) Bestia Umana & Italiano & 1893 & São Paulo \\
\hline 43) Tageblatt & Alemão & 1893 & São Paulo \\
\hline 44) Amico Delle Famigli & Italiano & 1893 & São Paulo \\
\hline 45) L'Avvenire & Italiano & 1894 & São Paulo \\
\hline 46) La Tribuna Italiana & Italiano & 1894 & São Paulo \\
\hline 47) Il Secolo & Italiano & 1894 & São Paulo \\
\hline 48) O Progresso & Português e Francês & 1894 & São Paulo \\
\hline 49) La Iberia & Espanhol & 1894 & São Paulo \\
\hline 50) Bolletino Ufficiale Della Camara Italiana & Italiano & 1894 & São Paulo \\
\hline 51) Il Popolo & Italiano & 1894 & São Paulo \\
\hline 52) Il Ficcanaso & Italiano & 1895 & São Paulo \\
\hline 53) L'Eclaireur & Francês & 1895 & São Paulo \\
\hline 54) Le Bulletin Français & Francês & 1895 & São Paulo \\
\hline 55) Bios & Italiano & 1896 & São Paulo \\
\hline 56) La Birichina & Italiano & 1896 & São Paulo \\
\hline 57) La Cronaca & Italiano & 1897 & São Paulo \\
\hline 58) La Penna & Italiano & 1897 & São Paulo \\
\hline 59) La Gaceta Española & Espanhol & 1897 & São Paulo \\
\hline 60) Pensamento e Arte & Português e Italiano & 1897 & São Paulo \\
\hline 61) Banana Freguezes & Italiano & 1897 & São Paulo \\
\hline 62) Capitan Fracassa & Italiano & 1897 & São Paulo \\
\hline 63) Deutsche-Zeitung & Alemão & 1897 & São Paulo \\
\hline 64) Il Secolo XX & Italiano & 1897 & São Paulo \\
\hline 65) Il Risveglio & Italiano & 1898 & São Paulo \\
\hline 66) L'Operario & Italiano & 1898 & São Paulo \\
\hline 67) Il Tribuno & Italiano & 1898 & São Paulo \\
\hline 68) La Luz & Espanhol & 1898 & São Paulo \\
\hline 69) Al Assmahy & Sírio & 1898 & São Paulo \\
\hline 70) XX de Settembre & Italiano & 1898 & São Paulo \\
\hline 71) El Diario Español & Espanhol & 1898 & São Paulo \\
\hline 72) Il Monello & Italiano & 1898 & São Paulo \\
\hline
\end{tabular}




\begin{tabular}{|c|c|c|c|}
\hline Jornal & Idioma & Ano & Cidade \\
\hline 73) O Grito do Povo & $\begin{array}{l}\text { Português, Espanhol } \\
\text { e Italiano }\end{array}$ & 1899 & São Paulo \\
\hline 74) El Grito Del Pueblo & Espanhol & 1899 & São Paulo \\
\hline 75) Gazetta del Papolo & Italiano & 1899 & São Paulo \\
\hline 76) Zazá & Italiano & 1899 & São Paulo \\
\hline 77) Al-Munazer & Sírio & 1899 & São Paulo \\
\hline 78) Cristoforo Colombo & Italiano & 1900 & São Paulo \\
\hline 79) Der Hausfreund & Alemão & 1900 & São Paulo \\
\hline 80) L’Usignuolo & Italiano & 1900 & São Paulo \\
\hline 81) Il SEcolo & Italiano & 1900 & São Paulo \\
\hline 82) La Voz de España & Espanhol & 1900 & São Paulo \\
\hline 83) L'Italiano & Italiano & 1900 & São Paulo \\
\hline 84) Cara-Dura & Italiano & 1900 & São Paulo \\
\hline 85) La Parola Dei Socialisti & Italiano & 1900 & São Paulo \\
\hline 86) La Campana di Piedigrotta & Italiano & 1900 & São Paulo \\
\hline 87) Avanti & Italiano & 1900 & São Paulo \\
\hline 88) L'Azione Anarchica & Italiano & 1900 & São Paulo \\
\hline 89) Chronache & Italiano & 1901 & São Paulo \\
\hline 90) $1^{\circ}$ de Maggio & Italiano & 1901 & São Paulo \\
\hline 91) L'Asino & Italiano & 1901 & São Paulo \\
\hline 92) Le Messager de Saint Paul & Francês & 1901 & São Paulo \\
\hline 93) La Italia Democratica & Italiano & 1901 & São Paulo \\
\hline 94) La Terza Roma & Italiano & 1901 & São Paulo \\
\hline 95) Il Ragno & Italiano & 1901 & São Paulo \\
\hline 96) La Reclame & Italiano & 1901 & São Paulo \\
\hline 97) Fieramosca & Italiano & 1902 & São Paulo \\
\hline 98) La Tribuna Española & Espanhol & 1902 & São Paulo \\
\hline 99) Il Colono Italiano Al Brasile & Italiano & 1902 & São Paulo \\
\hline $\begin{array}{l}\text { 100) Boletin de la sociedade española de } \\
\text { socorros mutuos e instruccion }\end{array}$ & Espanhol & 1902 & São Paulo \\
\hline 101) Il Passatempo & Italiano & 1902 & São Paulo \\
\hline 102) La Birichina & Italiano & 1902 & São Paulo \\
\hline 103) L'Amico de Lavoratore & Italiano & 1902 & São Paulo \\
\hline 104) L’Asino & Italiano & 1902 & São Paulo \\
\hline 105) La Moda Del Brasile & Italiano & 1902 & São Paulo \\
\hline 106) Lucifero & Italiano & 1902 & São Paulo \\
\hline 107) La Gogna & Italiano & 1902 & São Paulo \\
\hline 108) La Petite Revue & Francês & 1902 & São Paulo \\
\hline 109) O Livre Pensador & Português e italiano & 1902 & São Paulo \\
\hline 110) Il Romanziere Economico & Italiano e Português & 1902 & São Paulo \\
\hline 111) Le Journal Français Du Brésil & Francês & 1902 & São Paulo \\
\hline 112) Biezertung & Alemão & 1902 & São Paulo \\
\hline 113) Ar-Romouz & Árabe & 1902 & São Paulo \\
\hline 114) La voz de Destierro & Espanhol & 1903 & São Paulo \\
\hline 115) La Luce & Italiano e português & 1903 & São Paulo \\
\hline 116) La Nuova Gente & Italiano & 1903 & São Paulo \\
\hline 117) Il Giorno & Italiano & 1903 & São Paulo \\
\hline 118) Al-Afkar & Sírio & 1903 & São Paulo \\
\hline 119) L'Indipendente & Italiano & 1904 & São Paulo \\
\hline 120) La Veritá & Italiano & 1904 & São Paulo \\
\hline
\end{tabular}




\begin{tabular}{|c|c|c|c|}
\hline Jornal & Idioma & Ano & Cidade \\
\hline 121) Corrieri Italiano & Italiano & 1904 & São Paulo \\
\hline 122) Litteratura Ed Arte & Italiano & 1904 & São Paulo \\
\hline 123) Il Commercio e L' Indusria & Italiano & 1904 & São Paulo \\
\hline 124) La Farfalla & Italiano & 1904 & São Paulo \\
\hline 125) Il Romanziere & Italiano e português & 1904 & São Paulo \\
\hline 126) La Battaglia & Italiano & 1904 & São Paulo \\
\hline 127) Sem Vergonha & Italiano & 1904 & São Paulo \\
\hline 128) El Tiempo & Espanhol & 1904 & São Paulo \\
\hline 129) El Loro & Espanhol & 1904 & São Paulo \\
\hline 130) L'Echo Del Braz & Italiano & 1904 & São Paulo \\
\hline 131) Il Risveglio Italiano & Italiano & 1904 & São Paulo \\
\hline 132) Il Giorno & Italiano & 1904 & São Paulo \\
\hline 133) Anima e Vita & Italiano & 1905 & São Paulo \\
\hline 134) L'Indipendente & Italiano & 1905 & São Paulo \\
\hline 135) Il Gazzettino Verde & Italiano & 1905 & São Paulo \\
\hline 136) La Toscana & Italiano & 1905 & São Paulo \\
\hline 137) Il Grillo Di Flora & Italiano & 1905 & São Paulo \\
\hline 138) Il Pungolo & Italiano & 1905 & São Paulo \\
\hline 139) Il Secolo & Italiano & 1906 & São Paulo \\
\hline 140) La Parola Dei Socialisti & Italiano & 1906 & São Paulo \\
\hline 141) L'Illustrazione Italo-Brasiliana & Italiano & 1906 & São Paulo \\
\hline 142) La Cronaca & Italiano & 1906 & São Paulo \\
\hline 143) Il Faro & Italiano & 1906 & São Paulo \\
\hline 144) Idéa Nova & Italiano & 1906 & São Paulo \\
\hline 145) Tira Prosa & Italiano & 1906 & São Paulo \\
\hline 146) Il Gazzettino & Italiano & 1906 & São Paulo \\
\hline 147) Il Teatro & Italiano & 1906 & São Paulo \\
\hline 148) Dzwon Polski & Polonês & 1906 & São Paulo \\
\hline 149) La Squilla & Italiano & 1906 & São Paulo \\
\hline 150) La Rivista & Italiano & 1907 & São Paulo \\
\hline 151) La Vita & Italiano & 1907 & São Paulo \\
\hline 152) Arte-Natureza & Português e Italiano & 1908 & São Paulo \\
\hline 153) O Immigrante & $\begin{array}{l}\text { Português, italiano, } \\
\text { francês, alemão, } \\
\text { russo e polonês }\end{array}$ & 1908 & São Paulo \\
\hline 154) Il Meridionale & Italiano & 1908 & São Paulo \\
\hline 155) Il Fiore & Italiano & 1908 & São Paulo \\
\hline 156) Corrieri Illustrato & Italiano & 1908 & São Paulo \\
\hline 157) Il Colono Italiano & Italiano & 1908 & São Paulo \\
\hline 158) Il Piccolo & Italiano & 1908 & São Paulo \\
\hline 159) La Vita Italiana Nel Barzile & Italiano & 1908 & São Paulo \\
\hline 160) La Zanzara & Italiano & s/ano & São Paulo \\
\hline 161) L’Onestá & Italiano & s/ano & São Paulo \\
\hline
\end{tabular}

Ao todo, o estado de São Paulo contabilizou 131 títulos em italiano, 14 em espanhol, 10 em alemão, 10 em francês, 4 sírios, 2 em volapuque, 1 jornal em russo e 1 periódico em 
polonês. Nota-se, com esses dados, o predomínio dos jornais em língua italiana, perfazendo aproximadamente $81,3 \%$ do total de títulos, enquanto 8,6\% eram espanhóis, 6,2\% eram em alemão, 6,2\% em francês, $2,4 \%$ sírios e 1,8\% em outros idiomas. Conclui-se que os títulos em italiano dominaram o cenário paulista, e muito se deve à imigração italiana no país, que ultrapassou a faixa de um milhão de pessoas.

Deve-se mencionar que existiram algumas publicações bilíngues, como o jornal $\mathrm{Il}$ Romanziere Econômico, de 1902, que era em português e italiano. Havia ainda títulos em mais de um idioma, como o jornal O Immigrante, de 1908, em português, italiano, francês, alemão, russo e polonês.

Figura 1 - A imprensa italiana se destacou nos primeiros 100 anos da imprensa paulista; abaixo, o jornal L'Immigrante, de 1883.

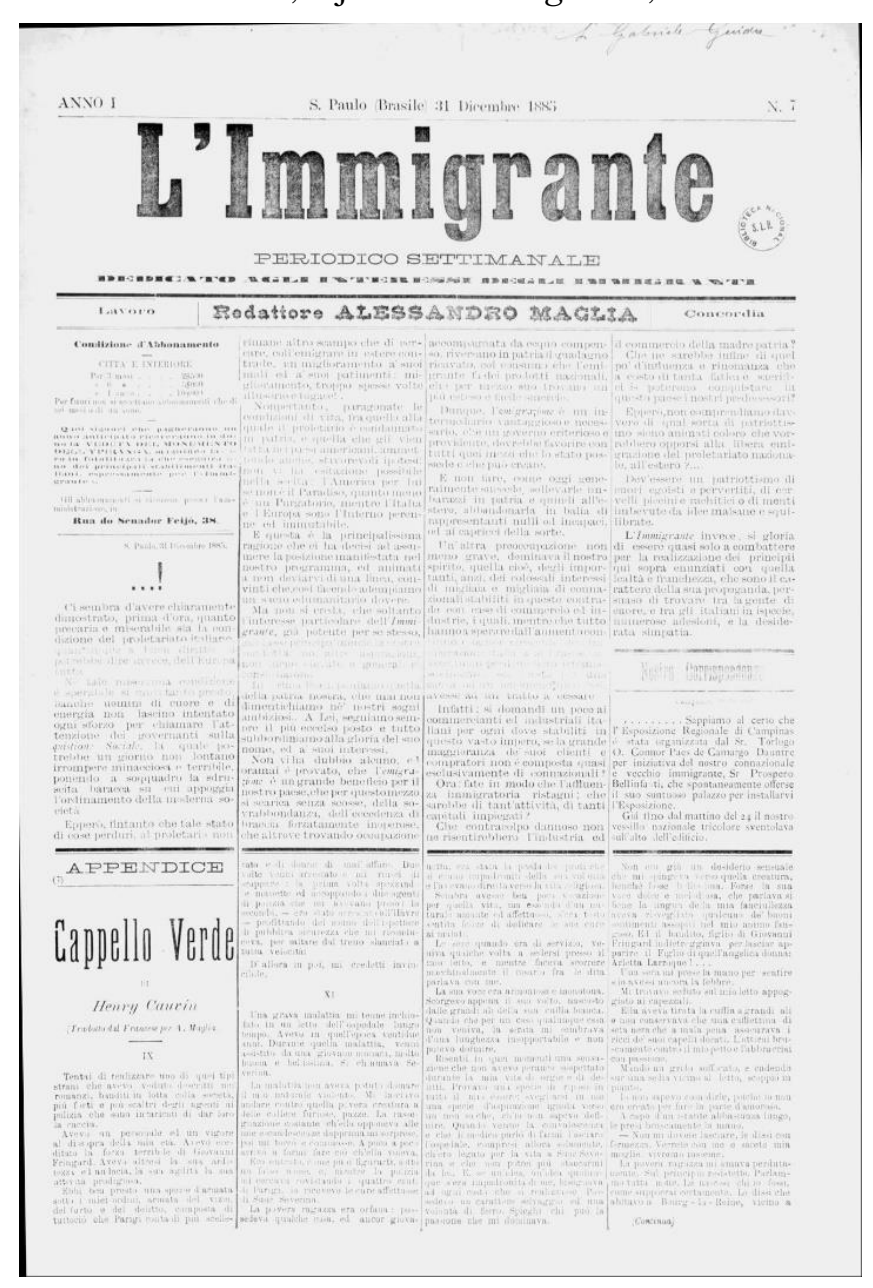

Fonte: Hemeroteca Digital da Biblioteca Nacional. 
Jornais em idioma estrangeiro no Brasil: um comparativo

De acordo com o Tomo Consagrado à Exposição Commemorativa do Primeiro Centenário da Imprensa Periódica no Brasil, o Catalogo de Jornaes Publicados no Paraná de 1853 até 1907 e A Imprensa Periódica de São Paulo de seus primórdios em 1823 até 1924 por Affonso A. De Freitas, circularam pelo Brasil 210 títulos em língua estrangeira, dos quais oito no estado do Amazonas, um no Ceará, três no Pará, dois na Paraíba, dois em Pernambuco, 33 no estado do Paraná e, em São Paulo, como já mencionado, 161 títulos.

O estado de São Paulo concentrou aproximadamente $76,6 \%$ de toda a produção de títulos em outro idioma; o estado do Paraná foi o segundo lugar, com 15,7\%. O estado do Amazonas ficou em terceiro lugar, com $3,8 \%$ das produções. Nota-se que a imigração foi um dos pontos determinantes para o predomínio de títulos no eixo sudeste-sul.

Gráfico 2 - Comparativo entre os estados do Brasil que tiveram jornais em outro idioma

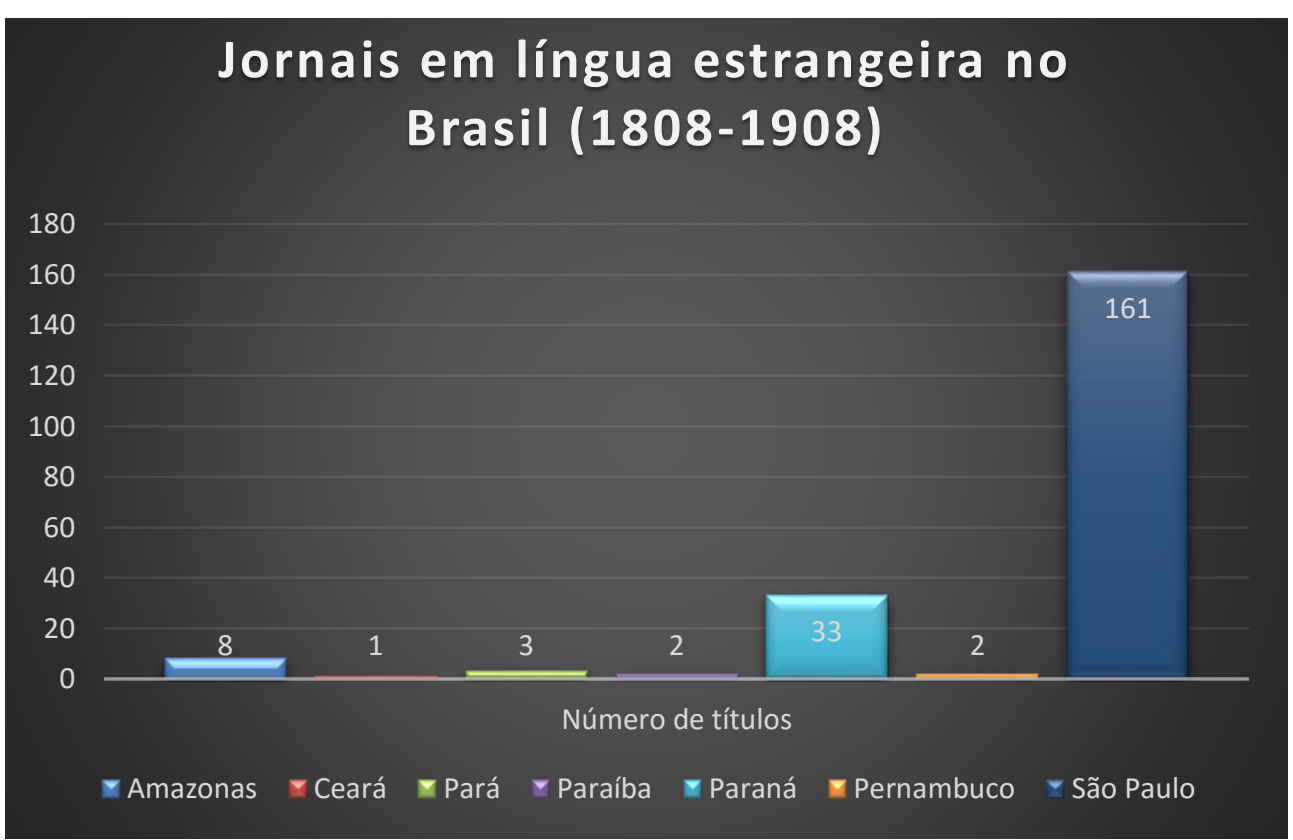

Fonte: Gráfico produzido pelo autor com dados do Tomo Consagrado à Exposição Commemorativa do Primeiro Centenário da Imprensa Periódica no Brasil; do Catalogo de Jornaes Publicados no Paraná de 1853 até 1907 e de A Imprensa Periódica de São Paulo de seus primórdios em 1823 até 1924 por Affonso A. De Freitas.

Uma das principais diferenças entre os estados em que circularam periódicos em outro idioma foi o predomínio de títulos em italiano em São Paulo, enquanto no Paraná boa parte dos jornais era em alemão. ${ }^{3}$ Já no estado do Amazonas, seis dos oito títulos eram em língua espanhola.

\footnotetext{
${ }^{3}$ No Paraná foram 20 títulos em alemão, perfazendo $60,6 \%$ do total.
} 
Quadro 2 - Jornais em língua estrangeira no Paraná

\begin{tabular}{|c|c|c|c|}
\hline Jornal & Idioma & Ano & Cidade \\
\hline Der Pionier & Alemão & 1881 & Curitiba \\
\hline Deutscher Waltemblatt & Alemão & 1882 & Curitiba \\
\hline Der Franen Lieblina & Alemão & 1886 & Curitiba \\
\hline Deutsch Echo & Alemão & 1886 & Curitiba \\
\hline Der Erzaller & Alemão & 1886 & Curitiba \\
\hline Deutsch Wolkszeitung & Alemão & 1887 & Curitiba \\
\hline Deutscher Blatter & Alemão & 1887 & Curitiba \\
\hline Der Beobachter & Alemão & 1889 & Curitiba \\
\hline Wuterhallemgsblatt & Alemão & 1890 & Curitiba \\
\hline Aus Natch zum Licht & Alemão & 1891 & Curitiba \\
\hline Deutsch Post & Alemão & 1892 & Curitiba \\
\hline L'Italia & Italiano & 1892 & Curitiba \\
\hline Gazeta Polska y Brazilye & Polonês & 1892 & Curitiba \\
\hline Illustrirtes Unterhaltemblatt & Alemão & 1893 & Curitiba \\
\hline Il Corriere d'Italia & Italiano & 1893 & Curitiba \\
\hline Il Lavoratore & Italiano & 1893 & Curitiba \\
\hline Deutscher Zeitung & Alemão & 1896 & Curitiba \\
\hline Die Hummel & Alemão & 1895 & Curitiba \\
\hline Der Franen Liebling & Alemão & 1896 & Curitiba \\
\hline Brasilianisch Bienenpfeg & Alemão & 1897 & Curitiba \\
\hline Kurier Paranski & Polonês & 1897 & Curitiba \\
\hline Zwiaj Kawiy & s/ identificação & 1898 & Curitiba \\
\hline Djablik Paransky & Polonês & 1898 & Curitiba \\
\hline Borsenhale & s/ identificação & 1898 & Curitiba \\
\hline Il Diritto & Italiano & 1899 & Curitiba \\
\hline Prawda & Polonês & 1900 & Curitiba \\
\hline Lo Spaurácchio & Italiano & 1902 & Curitiba \\
\hline Roboinik Paranski & Polonês & 1902 & Curitiba \\
\hline Corriere del Parana & Italiano & 1903 & Curitiba \\
\hline Die Wespe & Alemão & 1903 & Curitiba \\
\hline Das Boxende Koenguruh & Alemão & 1903 & Curitiba \\
\hline Polak k Brazylji & Polonês & 1904 & Curitiba \\
\hline Der Bazar & Alemão & 1908 & Curitiba \\
\hline
\end{tabular}

Fonte: Dados elaborados pelo autor de acordo com Martins (1908) no Catalogo de Jornaes Publicados no Paraná de 1853 até 1907.

Quadro 3 - Jornais em língua estrangeira no estado do Amazonas

\begin{tabular}{|r|l|l|l|l|}
\hline Jornal & & Idioma & Ano & Cidade \\
\hline 1) & La Voz de la España & Espanhol & 1901 & \\
\hline $\mathbf{2})$ & El Hispano Amazonense & Espanhol & 1901 & \\
\hline $\mathbf{3 )}$ & L'Italiano & Italiano & 1901 & \\
\hline $\mathbf{4 )}$ & La Stella D’Italia & Italiano & 1901 & \\
\hline $\mathbf{5 )}$ & Centro Español & Espanhol & 1902 & \\
\hline $\mathbf{6 )}$ & El Español & Espanhol & 1903 & \\
\hline $\mathbf{7})$ & La Union & Espanhol & 1903 & \\
\hline $\mathbf{8 )}$ & El Acre & Espanhol & 1901 & Departamento do Alto Acre \\
\hline
\end{tabular}

Fonte: Dados elaborados pelo autor com base no Tomo Consagrado à Exposição Commemorativa do Primeiro Centenário da Imprensa Periódica no Brasil. 
Quadro 4 - Jornais em língua estrangeira no Pará

\begin{tabular}{|c|c|c|c|c|}
\hline Jornal & & Idioma & Ano & Cidade \\
\hline 1) & La Voz de España & Espanhol & 1891 & \\
\hline & L'Eco Del Para & Italiano & 1898 & \\
\hline 3) & El Noticiero Español & Espanhol & 1899 & \\
\hline
\end{tabular}

Quadro 5 - Jornais em língua estrangeira no estado do Ceará

\begin{tabular}{|c|ccc|}
\hline Jornal & Idioma & Ano & Cidade \\
\hline E Pour si muouve & Italiano & 1875 & Fortaleza \\
\hline Fonte: Dados do Tomo Consagrado à Exposição Commemorativa do Primeiro Centenário da Imprensa \\
\multicolumn{3}{|c|}{ Periódica no Brasil. }
\end{tabular}

Quadro 6 - Jornais em língua estrangeira na Paraíba

\begin{tabular}{|l|l|l|l|l|}
\hline Jornal & \multicolumn{1}{c|}{ Idioma } & Ano & \multicolumn{1}{c|}{ Cidade } \\
\hline 1) & The Nort Parahyba Herald & Inglês & 1891 & \\
\hline 2) & The Parahyba Times & Inglês & 1894 & \\
Fonte: Dados elaborados pelo autor com base no Tomo Consagrado à Exposição Commemorativa do Primeiro \\
Centenário da Imprensa Periódica no Brasil.
\end{tabular}

Quadro 7 - Jornais em língua estrangeira em Pernambuco

\begin{tabular}{|c|c|c|c|c|}
\hline Jornal & & Idioma & Ano & Cidade \\
\hline 1) & Deutscher Kaempfer & Alemão & 1875 & Recife \\
\hline 2) & Dthynk & Alemão & 1875 & Recife \\
\hline 3) & The Pernambuco & Inglês & 1896 & \\
\hline
\end{tabular}

\section{Considerações finais}

O jornalismo paulista teve um alto desenvolvimento no século XIX e início do século XX, atingindo a marca de 1301 títulos. Dessa totalidade, 161 eram em idioma estrangeiro, o que aponta para a presença imigratória na região Sudeste.

No que tange à história do jornalismo no Brasil, a catalogação dos periódicos que circularam nos primeiros cem anos da imprensa no país se conjuga com a necessidade do IHGB em construir uma memória nacional, na qual a imprensa periódica brasileira teve seu contributo, tendo se desenvolvido junto com a nação brasileira. Um dos encarregados dessa tarefa, Affonso A. de Freitas, cumpriu seu dever de metodizar e catalogar os periódicos do estado de São Paulo, indo ao encontro dos objetivos do Instituto Histórico e Geográfico Brasileiro e também como parte de suas obrigações de membro correspondente. O inventário da imprensa periódica paulistana serviu para conhecer as origens da palavra impressa e do 
jornalismo paulistano e auxiliou na percepção de identidades editoriais dos periódicos, visto que muitos jornais expressam representações de si mesmos pelos títulos ou por sua apresentação no número inaugural. Apesar de ser uma lista sumária de títulos, o registro de Affonso A. de Freitas subsidia o início de muitas discussões e interrogações sobre o jornalismo em idioma estrangeiro no estado.

O catálogo A Imprensa Periódica de São Paulo de seus primórdios em 1823 até 1924 por Affonso A. De Freitas mostrou a pluralidade da imprensa, com seus títulos voltados à economia e à política, passando pelas belas artes e pela religião, até os jornais direcionados ao leitor imigrante. Os jornais em italiano dominaram o catálogo elaborado por Freitas, pois houve uma forte imigração italiana no estado. Os jornais em idiomas estrangeiros devem ser pensados como atores ativos da história de São Paulo e como fonte historiográfica, sendo, assim, uma intersecção entre história, jornalismo, tempo e memória.

\section{Referências}

BARBOSA, Marialva. História da Comunicação no Brasil. Petrópolis, Rio de Janeiro: Vozes, 2013.

COELHO, Edmundo Campos. As profissões imperiais - Medicina, Engenharia e Advocacia no Rio de Janeiro 1822-1930. Rio de Janeiro: Record, 1999.

COSTA, Alvaro Daniel. A comemoração do centenário da imprensa periódica brasileira no IHGB: Uma memória do jornalismo nacional (1908). Ponta Grossa, 2017. 110 p. Dissertação (Mestrado em História) - Universidade Estadual de Ponta Grossa, Ponta Grossa, 2017. Disponível

em: https://tede2.uepg.br/jspui/bitstream/prefix/2365/1/Alvaro\%20Costa.pdf. Acesso em: 29 dez. 2021.

COSTA, Alvaro Daniel. Jornais literários no Paraná: os cem primeiros anos da literatura na imprensa a partir dos catálogos comemorativos do IHGB. Uniletras, Ponta Grossa, n. 42, p. 1-15, 2020. Disponível

em: https://revistas2.uepg.br/index.php/uniletras/article/view/15296/209209213543. Acesso em: 29 dez. 2021.

FREITAS, Affonso A. A Imprensa Periodica de São Paulo desde os seus primórdios de 1823 até 1914. São Paulo: Diário Official, 1915.

GONÇALVES, Priscilla Soares. As festas e os cerimoniais na corte de D. João VI. ENCONTRO REGIONL DA ANPUH-RIO, 14., 2010, Rio de Janeiro. Anais [...]. Disponível em: https://www.encontro2010.rj.anpuh.org/resources/anais/8/1276742443_ARQUIVO_ArtigoAn puh.pdf. Acesso em: 10 jun. 2020. 
KLEIN, Herbert. A imigração espanhola no Brasil. São Paulo: Ed. Sumaré: FAPESP, 1994.

MARTINS, Romário. Catalogo dos jornaes publicados no Paraná de 1854 a 1907. Curytiba: Impressora Paranaense, 1908.

REVISTA DO INSTITUTO HISTÓRICO E GEOGRÁFICO BRASILEIRO. Tomo Consagrado à Exposição Commemorativa do Primeiro Centenário da Imprensa Periódica no Brazil. Rio de Janeiro: Imprensa Nacional, 1908. v. 1.

Submetido em: 10.05.2020.

Aprovado em: 15.12.2021. 